\title{
PHASE RELATIONS BETWEEN CAROTID PRESSURE AND ONGOING ELECTROCORTICAL ACTIVITY *
}

\author{
BARBARA B. WALKER ${ }^{1}$ and J. MICHAEL WALKER ${ }^{2}$ \\ 'Ann Arbor Veterans Administration Medical Center and University of Michigan and ' Mental Health Research Institute, University of \\ Michigan, Ann Arbor, MI (U.S.A.)
}

(Accepted January 21st, 1983)

Key words: electroencephalogram-carotid artery—alpha wave-human

\begin{abstract}
The behavioral significance of changes in the cardiovascular system has been a major source of controversy in psychophysiology. In view of this, it is surprising that so few studies have examined the relationship between cardiac events and electrocortical (EEG) activity in human subjects. In the present study, this relationship was examined by comparing phase, amplitude and frequency of EEG activity sampled during systolic and diastolic pressure recorded from the carotid artery of resting subjects. The results indicated that rhythmic oscillations of the EEG (particularly those in the alpha range) were time-locked to the carotid pressure wave, and EEG samples taken during systolic and diastolic pressure were distinctly out of phase. In addition, EEG activity sampled during systolic pressure was comprised of slower frequencies than EEG activity sampled during diastolic pressure. It was suggested that the relationship between cardiac events and behavior may be mediated in part by influences of the cardiovascular system on electrocortical rhythms.
\end{abstract}

\section{INTRODUCTION}

The autonomic nervous system is often conceptualized as an effector system that contains some afferent fibers in order to maintain physiological homeostasis. This view persists in spite of the fact that most of the autonomic nervous system is comprised of afferent rather than efferent fibers (Agostoni et al., 1957; Cragg and Evans, 1960), and these afferent fibers are known to exert a wide variety of extra-homeostatic effects.

In the case of the cardiovascular system, for example, it is commonly assumed that afferent inpulses from baroreceptors serve only to regulate blood pressure. There are now numerous reports, however, to indicate that baroreceptors also have profound effects on a variety of systems that are unrelated to cardiovascular control. Stimulation of

\footnotetext{
* Parts of this paper were presented to the Society for Psychophysiological Research in Minneapolis, MI, in October, 1982
}

baroreceptors in the carotid sinus inhibits motor activity (Koch, 1932), electrocortical activity (Bonvallet et al., 1954; Nakao et al., 1956), monosynaptic reflexes (Bonvallet et al., 1954), sham rage (Bartorelli et al., 1960; Baccelli et al., 1965), pyramidal tract cells in the motor cortex (Coleridge et al., 1976), single cell firing to skin stimulation in the nucleus cuneatus (Gahery and Vigier, 1974), sweat gland activity and nictitating membrane activity in cats (Horowitz and Kaufman, 1979).

It has also been proposed that the inhibition resulting from increases in baroreceptor firing is behaviorally significant (Lacey, 1967). Cardiac acceleration is associated with slower reaction times and impaired visual perception whereas cardiac deceleration is associated with faster reaction times and enhanced visual perception (Lacey et al., 1963; Lacey, 1967; Lacey, 1972; Duncan-Johnson and Coles, 1974; Sandman et al., 1977). Attempts to relate behavioral changes to differential firing of 
baroreceptors within a cardiac cycle, however, have yielded equivocal results. Even when faster reaction time or enhanced visual perception has been found early in the cardiac cycle (when baroreceptors fire minimally) compared to late (when baroreceptors fire maximally), the effects have not been robust (Birren et al., 1963; Callaway and Layne, 1964; Sandman et al., 1977).

In view of these data and the controversy surrounding the behavioral significance of cardiac events (Elliott. 1972; Lacey and Lacey, 1974; Carroll and Anastasiades, 1978; Obrist, 1976), it is surprising that so few studies have examined the relation between cardiac events and central nervous system activity in human subjects. Some early studies suggested that cardiac events were related to human electroencephalographic (EEG) activity (Callaway, 1965; Callaway and Buchsbaum, 1965; Callaway and Layne, 1964), but details of the relationship are difficult to ascertain from these reports. More recently, three experiments from our laboratory demonstrated that average evoked potentials (AEPs) changed as heart rate (Walker and Sandman, 1979) and carotid pressure (Walker and Sandman, 1982) fluctuated normally. In these experiments, changes in cardiovascular events were also related to AEPs recorded from the right and left cerebral hemispheres differently, suggesting that hemispheric specialization may play a role in autonomic-brain-behavior relationships.

The results of these studies raise questions regarding the relationship between cardiac events and ongoing electrocortical activity. First, do normal fluctuations in the cardiovascular system coincide with changes in phase or frequency of EEG? If so, are these changes reflected differently in the two cerebral hemispheres? In the following experiment, these questions were addressed by recording ongoing EEG activity from the right and left occipital regions of resting subjects during both systolic (when baroreceptors fire maximally) and diastolic pressure (when baroreceptors fire minimally). Based upon findings from previous neurophysiological and behavioral experiments, it was hypothesized that distinct relationships between carotid pressure and ongoing EEG activity would emerge.

\section{METHOD}

\section{Subjects}

Twelve volunteers ( 6 male and 6 female) who were between the ages of 18 and 39 , in good general health, right-handed, and had $20 / 20$ corrected vision served as subjects in the experiment.

\section{Procedure}

Subjects were tested in a sound-attenuating chamber with recording and programming equipment housed in an adjacent room. Physiological recordings were obtained with a Grass Model 7D polygraph equipped with appropriate preamplifiers and driver amplifiers.

Subjects reclined in a comfortable chair while transducers were attached for recording heart rate, respiration, EEG, eye movements and carotid pressure. Care was taken to ensure that subjects were in a position that did not entail continuous postural tension. They were instructed to relax, breathe regularly and keep their eyes fixated on the center of the screen in front of them.

After a few minutes of recording, the highest and lowest points of the carotid pressure wave (corresponding to systolic and diastolic pressure) were determined and read into a microprocessor running under a UCSD PASCAL host program. When this threshold was met for either systolic or diastolic pressure, the two channels of EEG (right and left hemispheres), carotid pressure and electrocardiogram (ECG) were digitized by a 12 bit converter at $100 \mathrm{H} z$ for a period of $500 \mathrm{~ms}$. Half (50) of the sampling periods were initiated at systolic and half (50) at diastolic pressure in an alternating sequence. A minimum of $3 \mathrm{~s}$ elapsed between sampling periods.

Carotid pressure. Photoplethysmographs ${ }^{2}$ were

\footnotetext{
It is important to note that the samples collected after approximately $300 \mathrm{~ms}$ were confounded by the occurrence of the systolic or diastolic pressure associated with the next wave. Therefore, only samples recorded during the first $300 \mathrm{~ms}$ were associated exclusively with systolic or diastolic pressure. A period of $500 \mathrm{~ms}$ was chosen to enable close comparison of these data with other studies of evoked potentials recorded during systolic and diastolic pressure.

${ }^{2}$ These plethysmographs were designed and constructed by J.M.W.
} 
taped over both the right and left carotid arteries of each subject, but recordings were obtained only from the one placed on the left side. This procedure was followed because in past experiments (Walker and Sandman, 1979; Walker and Sandman, 1982) cardiac activity was related to right and left hemispheres differently, and the kinesthetic feedback from a unilaterally placed plethysmograph could contribute to this latcralization (J. Lacey, personal communication). The plethysmographs were constructed from two infrared light reflection emitter sensor arrays (Fairchild, FPA106) encased in epoxy. The emitter was coupled to the $12 \mathrm{~V}$ power supply of the polygraph through a $200 \Omega$ resistor to limit current flow. Integrated circuit operational amplifiers, configured as current amplifiers, were used to interface the phototransistor to the polygraph. The signal was amplified by an $\mathrm{AC}$ preamplifier with a half amplitude low frequency of 0.3 and a half-amplitude high frequency of $15 \mathrm{~Hz}$. This provided a very clear recording of carotid pressure with few artifacts other than those associated with swallowing. EEG samples taken during swallowing were deleted from all analyses.

EEG. Sites designated by the International 10-20 system (Jasper, 1958) as $\mathrm{O}_{1}$ and $\mathrm{O}_{2}$ and both mastoids were rubbed briskly with acetone to reduce resistance. $\mathrm{Ag}-\mathrm{AgCl}$ electrodes filled with Grass EEG Creme were then affixed to the scalp with collodion. Electrodes at $\mathrm{O}_{1}$ and $\mathrm{O}_{2}$ were connected to linked mastoids to permit unipolar recordings from the right and left occipital cortex. Pairs of electrodes showing more than $10 \mathrm{k} \Omega$ impedence were replaced. The signal was amplified using a half-amplitude low frequency of $1 \mathrm{~Hz}$ and a half-amplitude high frequency of $35 \mathrm{~Hz}$ (see Goff, 1974). No ECG artifacts were evident in any of the EEG recordings.

$E C G$. Grass $\mathrm{Ag}-\mathrm{AgCl}$ cup electrodes filled with ECG Sol were attached to the area of the lower left rib and the right collar bone of each subject after these areas were swabbed with acetone. The signal was amplified by a Grass AC preamplifier and also processed by a cardiotachometer to provide beat-by-beat heart-rate recordings.

Respiration. A Beckman Bellows Pneumograph was placed around the chest of each subject, and the varying voltage was amplified by a Grass AC preamplifier using a time constant of $0.8 \mathrm{~s}$. EEG samples taken during changes in respiration were deleted from all analyses.

Eye movements. $\mathrm{Ag}-\mathrm{AgCl}$ electrodes were placed next to and below the left eye about $2 \mathrm{~cm}$ from the orbital cavity using Grass ECG Sol. The purpose of this measure was to enable deletion of all trials involving eye movements or eye blinks.

\section{RESULTS}

The 50 samples of EEG, carotid pressure and ECG recorded during systolic and diastolic pressure were averaged and graphed for each subject separately. This yielded 8 graphs for each subject: average right and left occipital EEG activity, average carotid pressure and average ECG recorded during both phases of carotid pressure. These data were then averaged across subjects, and Fig. 1 illustrates the mean EEG, carotid pressure and ECG recorded during systolic and diastolic pressure. The figure verifies that sampling periods were in fact initiated during systolic and diastolic pressure.

\section{Phase and amplitude differences}

The question arises regarding what might be expected if there were no relationship between EEG activity and carotid pressure. In order to determine this empirically, a $10 \mathrm{~Hz}$ sine wave (to simulate EEG) was sampled 100 times at time intervals equivalent to those in the initial experiment. In an alternating sequence, half of the samples were averaged together as systolic controls, and the other half were averaged together as diastolic controls. This experiment was repeated 12 times to simulate the initial experiment with 12 different subjects.

Each individual waveform revealed activity at a frequency of $10 \mathrm{~Hz}$, but the amplitude and phase of this activity differed markedly from one waveform to the next. As a result, when averages of the 12 separate runs were computed, systolic and diastolic controls did not differ in any significant manner. Therefore, if there were no relationship between EEG and carotid pressure, one would expect no significant differences to emerge be- 


\section{RIGHT HEMISPHERE}

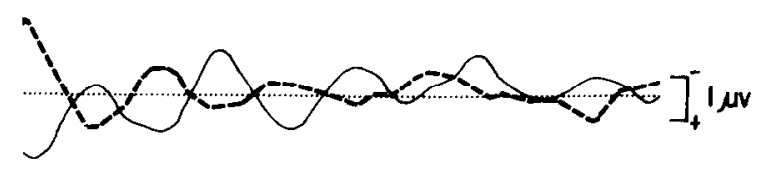

\section{LEFT HEMISPHERE}
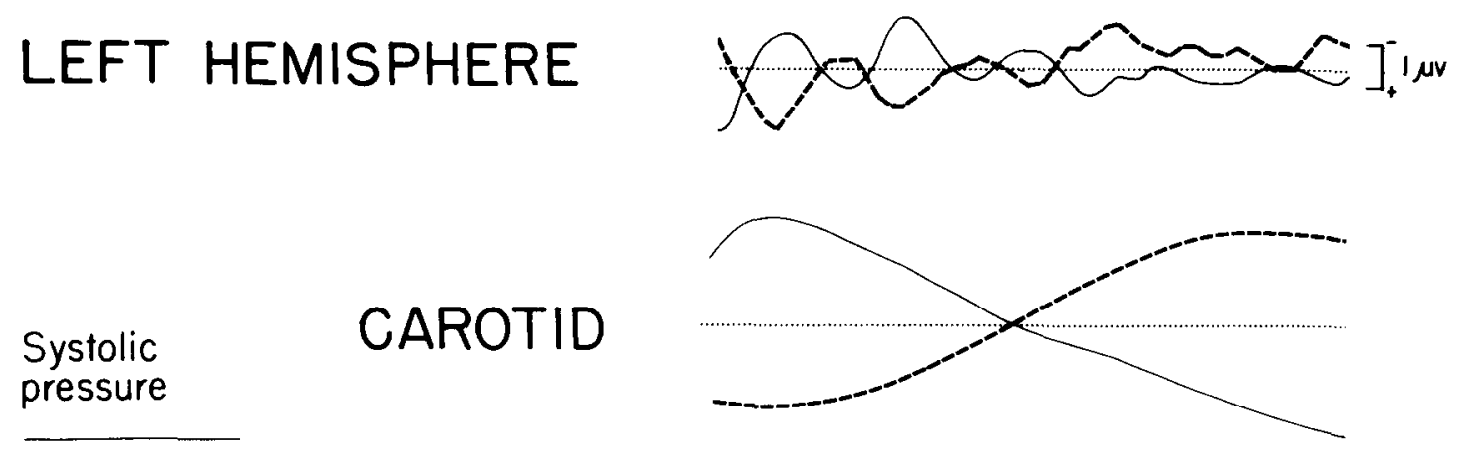

Diastolic
pressure
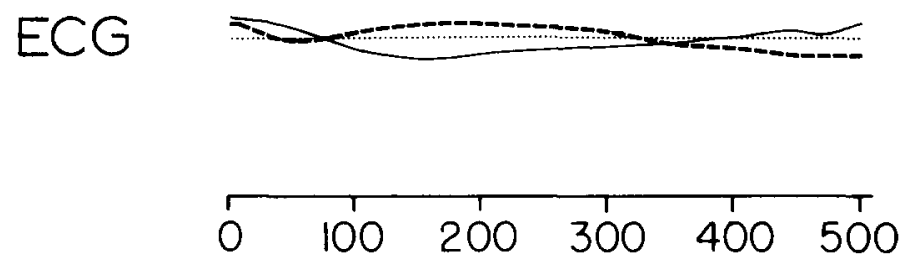

Fig. 1. Average EEG activity from scalp overlying the right and left occipital regions, average carotid pressure, and average ECG recorded for $\$ 00 \mathrm{~ms}$ following systolic and diastolic pressure.

tween systolic and diastolic pressure after averaging 50 sampling periods of EEG together across 12 subjects.

As shown in Fig. 1, this was clearly not the case. Not only was there a rhythmic oscillation of the EEG time-locked to the carotid pressure wave, but this oscillation was distinctly out of phase at systolic and diastolic pressure. Furthermore, it is evident from the average $E C G$ recordings that these changes were not artifacts arising from electrical activity of the heart.

To investigate these differences statistically, latencies and amplitudes of the first 5 positive (P1-P5) and 5 negative (N1-N5) peaks were recorded for each of the 4 waveforms from each subject. Since identification of these peaks was sometimes difficult due to variability, two independent judges chose the peaks. In the few cases of discrepancy, consensus was reached with the assistance of a third judge. These data were than analyzed using a 12 (subjects) $\times 2$ (systolic/diastolic) $\times 2$ (hemispheres) repeated measures anal$y$ sis of variance.

The latency of the first positive peak recorded during systolic pressure differed significantly, $F(1,11)=7.59 ; \quad P<0.02$, from the latency recorded at diastolic pressure. This peak occurred at an average of $15 \mathrm{~ms}$ in waveforms recorded during systolic pressure but was delayed until $36.7 \mathrm{~ms}$ during diastolic pressure. In order to be certain that this effect did not result from changes in only a few subjects, data from each individual subject were examined. The latency of the first positive peak occurred later at systolic than at diastolic pressure in 9 of 12 subjects. Although the latencies of some of the later peaks recorded at diastolic 


\section{LEFT HEMISPHERE RIGHT HEMISPHERE}

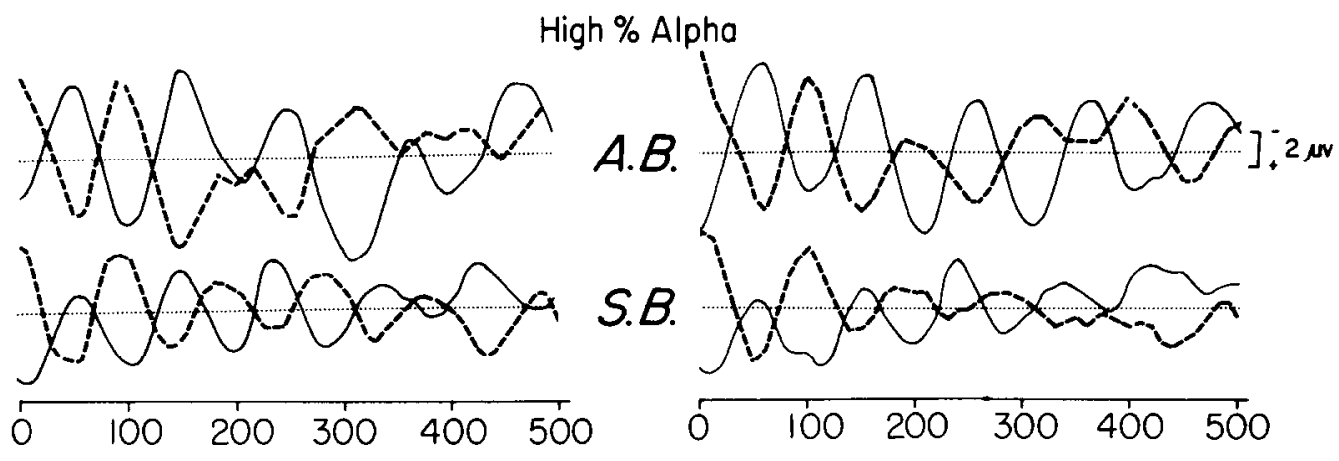

Low \% Alpha
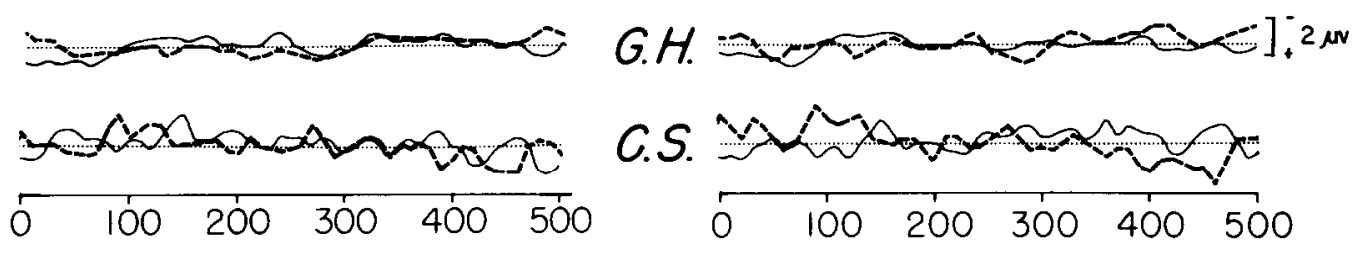

Systolic pressure

Diastolic pressure

Fig. 2. Average EEG activity during systolic and diastolic pressure recorded from two subjects with a high percentage of alpha activity (A.B. and S.B.) and two subjects who showed little alpha activity (G.H. and C.S.).

pressure were also longer than those recorded at systolic pressure, these differences were not statistically significant. Amplitudes also did not differ significantly among any of the waveforms.

Examination of data from individual subjects indicated that this lack of statistical significance probably resulted from large individual differences. This observation, together with the observation that the EEG activity that was timelocked to carotid pressure appeared to be in the range of $8-12 \mathrm{~Hz}$ (see Fig. 1), suggested that carotid pressure may be related more to phase of alpha than to waves of other frequencies. To investigate this hypothesis, the two subjects with the most alpha and two with relatively little alpha in their polygraph records were identified by a laboratory technician who was unaware of the experimental hypotheses. The waveforms recorded from these 4 individual subjects are shown in Fig. 2. The figure illustrates that the relationship between carotid pressure and EEG was most evident when a high percentage of alpha was present in the EEG. The relationship hetween EEG and carotid pressure was difficult to discern in subjects who showed very little alpha activity.

In order to be certain that differences in electrocortical activity were related specifically to carotid pressure, three subjects were asked to return to the laboratory for a control session ${ }^{3}$. This session was identical to the experimental session with one major exception: samples of EEG were initiated by the experimenter (at intervals equiva-

\footnotetext{
${ }^{3}$ One subject showed a high percentage of alpha in the initial recordings (A.B. in Fig. 2), one a low percentage (C.S. in Fig. 2) and one a moderate amount.
} 

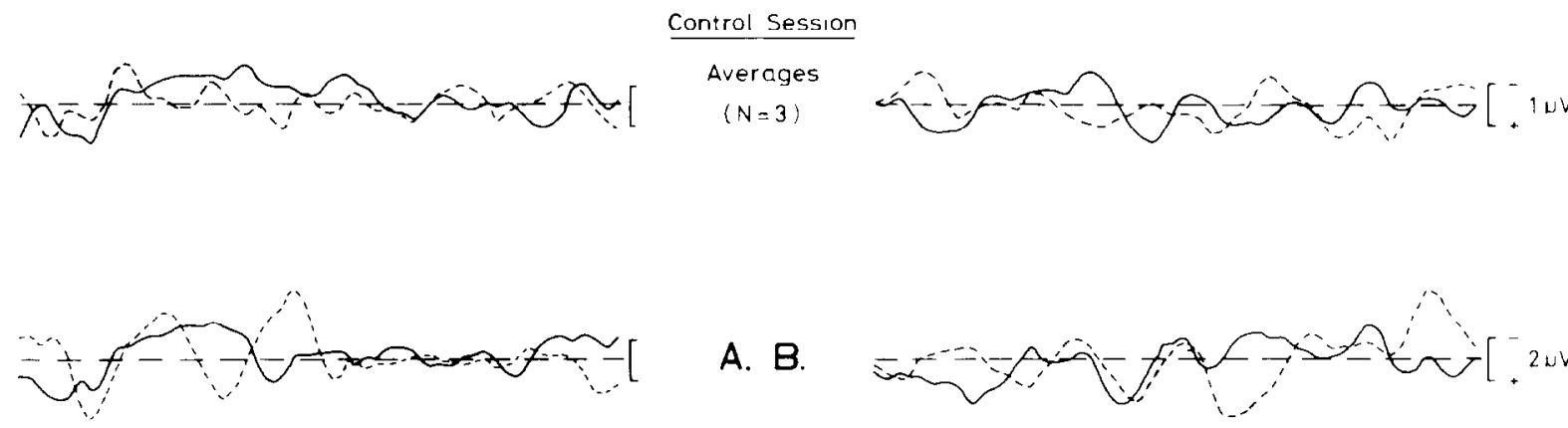

A. B.

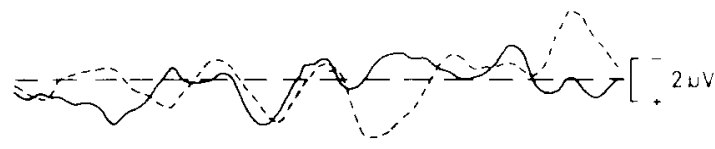

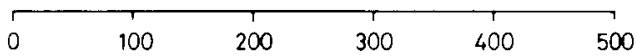

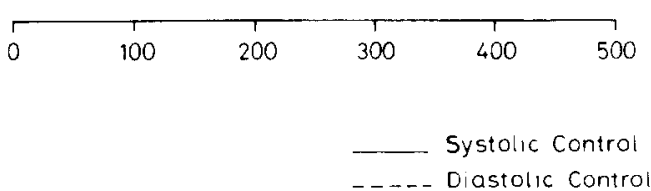

Fig. 3. Average EEG activity recorded from 3 subjects (A.B., C.S. and M.K.) irrespective of carotid pressure. Subject A.B. is shown alone to enable comparison with samples taken from this subject at systolic and diastolic pressure (see Fig. 2).

lent to those in the first session) without knowledge of carotid pressure. The EEG activity associated with the systolic control and diastolic control conditions were averaged as in the previous session, and the control data from subject A.B. (also shown in Fig. 2) and the averages of all 3 subjects are shown in Fig. 3. As expected, some oscillations were evident in the control waveforms, but these oscillations differed in their predominant rhythms, and no systematic differences emerged between systolic and diastolic controls. The alpha waves that were clearly time-locked to carotid pressure (see Figs. 1 and 2) were absent when samples were taken that were independent from the carotid pressure wave (see Fig. 3).

\section{Frequency differences}

To determine whether frequency components of the EEG differed during systolic and diastolic pressure, spectral analyses were performed on each of the 4 waveforms recorded from each subject. The spectral densities were estimated for 25 frequency bands ranging from 2 to $50 \mathrm{~Hz}$. These densities were then analyzed for each frequency band separately using 2 (systolic/diastolic) $\times 2$ (hemispheres) analyses of variance with repeated measures. As expected, these spectral analyses consistently revealed peaks at approximately 10 $\mathrm{Hz}$. There was significantly more slow activity in the $4 \mathrm{~Hz}$ band, however, during systolic than during diastolic pressure $(F(1,11)=9.96 ; P<$ 0.01 ) in all but one subject. This relationship was similar for the two hemispheres in hoth males and females, and no significant differences emerged for the other frequency bands.

\section{DISCUSSION}

The results of this experiment add to the growing body of evidence that the influence of autonomic activity on the brain extends beyond that required to maintain homeostasis. Rhythmic oscillations of the EEG were time-locked to the carotid pressure wave, and EEG samples taken during systolic and diastolic pressure were distinctly out 
of phase. These oscillations were primarily in the alpha range, suggesting that cardiac events may play some role in synchronizing alpha activity.

Given other neurophysiological evidence, it is possible to hypothesize neuronal activity that could account for these effects. Rhythmic activity in the cortex is almost totally dependent upon ascending impulses (Andersen and Anderson, 1968), specifically those generated in the thalamus (Ohmoto et al., 1978). Morison and Dempsey (1942) provided evidence that midline thalamic nuclei serve as alpha pacemakers, and Jasper and his colleagues $(1949,1954)$ discovered that these pacemakers are under the influence of the reticular activating system. Since the reticular formation is replete with afferent fibers from the viscera (see Voogd and Huijzen, 1979) it is possible that visceral changes can modulate electrocortical rhythms via changes in reticulo-thalamic impulses. In the case of the cardiovascular system, for example, baroreceptor impulses transmitted to the reticular system could influence electrocortical pacemakers in the thalamus resulting in EEG differences such as those found in the present study.

The role that cerebral blood flow may play in this process is unclear. It has long been known that cerebrospinal fluid pulsates with each heart beat (Bering, 1955), but the neuronal changes that might accompany these pulsations remain a mystery. Neuronal excitability could be altered by changes in oxygen and carbon dioxide that occur during one cardiac cycle (Forster and Stone, 1976), but this is highly speculative. Other evidence indicates that cerebral vasoconstriction occurs when systemic blood pressure is raised, and this vasoconstriction is related specifically to baroreceptor activity (Ponte and Purves, 1974). It is possible, therefore, that increased baroreceptor firing leads to cerebral vasoconstriction which in turn causes neuronal changes. The situation is complicated, however, because most investigations of the relation between cerebral blood flow, EEG and autonomic activity have focused on more long-term changes than the brief fluctuations that occur during one cardiac cycle. Thus, while it is certain that cerebral blood flow and electrocortical activity are closely coupled, the precise nature of this relationship is unknown.
Regardless of the mechanisms that are involved, it seems clear from the present experiment that phase of alpha is related to cardiovascular activity. Research on the functional significance of alpha suggests that phase may reflect fluctuations in cortical excitability (Lindsley, 1952; Komisaruk, 1977; Harter, 1967), serving as a 'neuronic shutter' that can impair or facilitate sensory intake (Callaway and Alexander; 1960; Nunn and Osselton, 1974). The perceived intensity of light flashes (Callaway, 1965), reaction times (Lansing, 1957; Dustman and Beck, 1965; Callaway and Yaeger, 1960), evoked responses (Callaway and Layne, 1964; Remond and Lesvre, 1967) and galvanic skin responses (Nunn and Osselton, 1974) all vary as a function of the phase of alpha at which stimuli occur. In view of this, it seems possible that the facilitation and impairment of sensory intake associated with cardiac changes (Lacey, 1967; Lacey and Lacey, 1974) may be mediated by the influence of cardiac events on various electrocortical rhythms.

Behavioral changes may also be related to frequency of electrocortical rhythms, and the Laceys $(1967$; 1974) have drawn attention to experiments with animals demonstrating that physical distention of the carotid sinus leads to a profound slowing of electrocortical activity (Bonvallet et al., 1954). It has been unclear, however, whether these findings bear any relevance to normal physiological activity occurring in human beings. The present findings suggest that they do; it appears that in healthy, intact human beings, electrocortical activity slows each time the carotid sinus is normally distended during systole. Therefore, it seems that frequency changes in the EEG may also play some role in cardiac-brain-behavior relationships.

Research from a variety of disciplines has begun to suggest interrelationships between cardiac events, brain lateralization and behavior. For example, both the right hemisphere (Dustman et al., 1976; Heilman and Abell, 1980) and decreases in heart rate (Lacey, 1976) have been related to attention, whereas both the left hemisphere (Donchin et al., 1977) and increases in heart rate (Lacey, 1967; Campos and Johnson, 1966; 1967) have been associated with logical, verbal processes. Furthermore, 
evoked responses recorded during different cardiac events differ significantly in the right and left hemispheres (Walker and Sandman, 1979; Walker and Sandman, 1982), suggesting that the relationship between cardiac events and behavior may result from different types of activity occurring in the two cerebral hemispheres. The present study revealed that the relationship between EEG and carotid pressure is similar for the two hemispheres. Thus, interactions between cardiac events, brain lateralization and hehavior cannot be attributed simply to changes in background EEG activity. These relationships are undoubtedly very complex and involve much higher levels of integration than has previously been assumed.

\section{ACKNOWLEDGEMENTS}

The research reported in this paper was supported by the Veterans $\Lambda$ dministration and grants from the Vice President for Research (136162), the Biomedical Research Council (019007) and the Department of Psychiatry (275829) at the University of Michigan. The invaluable technical assistance provided by $\mathrm{Mr}$. Philip Johnson and the contributions of Mr. Aaron Betel, Mr. Alan Elliott, Ms. Mildred Kemp, Mr. Scott Monteith, and Mr. Brian Wolff are gratefully acknowledged.

\section{REFERENCES}

Agostoni, E., Chinnock, J.E., Daly, M.D. and Murray, J.G. (1957) Functional and histological studies on the vagus and its branches to the heart, lungs and abdominal viscera in the cat. J. Physiol., (Lond.), 135: 182-205.

Andersen, P. and Andersson, S.A. (1968) The Physiological Basis of the Alpha Rhythm, Appleton-Century-Crofts, New York.

Baccelli, G., Guazzi, M., Libretti, A. and Zanchetti, A. (1965) Pressoceptive and chemoceptive aortic reflexes in decorticate and in decerebrate cats. Amer. J. Physiol, 208: 708-714

Bartorelli, C., Bizzi, E., Libretti, A. and Zanchetti, A. (1960) Inhibitory control of sinocarotid pressoceptive afferents on hypothalamic autonomic activity and sham rage behavior. Archiv. ital. Biol., 98: 308-326.

Bering, E.A. (1955) Choroid plexus and arterial pulsation of cerebrospinal fluid. Arch. Neurol. Psychiat., 13: 165-172.

Birren, J., Cardon, P. and Phillips, S. (1963) Reaction time as a function of the cardiac cycle in young adults. Science, 140: $195-196$.
Bonvallet, M., Dell, P. and Hiebel, G. (1954) Tonus sympathetique et activité electrique corticale. Electroenceph. clin. Neurophysiol., 6: 119-144.

Bonvallet, M., Dell, P. and Hugelin, A. (1954) Influence de l'adrenaline sur le controle reticulaire des activités corticale et spinale. J. Physiol. (Paris), 46: 262-265.

Callaway, E. (1965) Response speed, the EEG alpha cycle, and the autonomic cardiovascular cycle. In A.T. Welford and J.E. Birren (Eds.), Behavior, Aging and the Nervous System, Thomas, Springfield, IL, pp. 217-233.

Callaway, E. and Alexander, J.D. (1960) The temporal coding of sensoty data: an investigation of two theories. $J$. gen. Psychol, 62: 293-309.

Callaway, E. and Buchsbaum, M. (1965) Effects of cardiac and respiratory cycles on averaged visual evoked responses. Electroenceph. clin. Neurophysiol., 19: 476-480.

Callaway, E. and Layne, R. (1964) Interaction between the visual evoked response and two spontaneous biological rhythms: the EEG alpha cycle and the cardiac arousal cycle. Ann. N.Y. Acad. Sci, 112: 424-431.

Callaway, E. and Yaeger, C.L. (1960) Relationship between reaction time and electroencephalographic alpha phase. $S c i-$ ence, 132: 1765-1766.

Campos, J. and Johnson, H. (1966) The effects of verbalization instructions and visual attention on heart rate and skin conductance. Psychophysiology, 2: 305-310.

Campos, J. and Johnson, H. (1967) Affect, verbalization and directional fractionation of autonomic responses. Psychophysiology, 3: 285-290.

Carroll, D. and Anastasiades, P. (1978) The behavioral significance of heart rate: the Lacey's hypothesis. Biol. Psych. 7: 249-275.

Coleridge, H.M., Coleridge, J.C. and Rosenthal, F. (1976) Prolonged inactivation of cortical pyramidal tract neurones in cats by distension of the carotid sinus. J. Physiol., 256: 635-649.

Cragg, B.G. and Evans, D.H. (1960) Some reflexes mediated by the afferent fibers of the abdominal vagus in the rabbit and cat. Exp. Ncurol., 2: 112.

Donchin, E., McCarthy, G. and Kutas, M. (1977) Electroencephalographic investigations of hemispheric specialization. In J.E. Dresmedt (Ed.), Language and Hemispheric Specialization in Man: Cerebral Event - related Potentials. Progress in Clinical Neurophysiology, Vol. 3, Barger. New York. pp. 212-243.

Duncan-Johnson, C. and Coles. M. (1974) Heart rate and disjunctive reaction time: the effects of discrimination requirements. J. Exp. Psychol., 103: 1160-1168.

Dustman, R.E. and Beck, E.C. (1965) Phase of alpha brain waves, reaction time and visually evoked potentials. Electroenceph. clin. Neurophysiol., 18: 433-440.

Dustman, R.E.. Schenkenberg, T. and Beck, E.C. (1976) The development of the evoked response as a diagnostic and evaluative procedure. In R. Karrer (Ed.), Developmental Psychophysiology of Mental Retardation. Thomas, Springfield, IL, pp. 247-310.

Elliott, R. (1972) The significance of heart rate for behavior: a 
critique of Lacey's hypothesis. J. Pers. Soc. Psychol., 22: 398-409.

Forster, A. and Stone, T.W. (1976) Evidence for a cardiovascular modulation of central neuronal activity in man. Exp. Neurol., 51: 141-149.

Gahery, Y. and Vigier, D. (1974) Inhibitory effects in the cuneate nucleus produced by vagoaortic afferent fibers. Brain Res., 75: 241-246.

Goff, W.R. (1974) Human average evoked potentials: procedures for stimulating and recording. In R.F. Thompson and M.M. Patterson (Eds.), Bioelectric Recording Techniques, Part B, Academic Press. New York, pp. 102-156.

Harter, M.R. (1967). Excitability cycles and cortical scanning: a review of two hypotheses of central intermittency in perception. Psychol. Bull., 68: 47-58.

Ieilman, K. and Abcll, T. (1980) Right hemisphere dominance for attention: the mechanism underlying hemispheric asymmetries of inattention (neglect). Neurology, 30: 327-330.

Horowitz, I.S. and Kaufman, A.I. (1979) Effects of baroreceptor activation on spontaneous activity in the sweat glands and nictitating membrane of the cat. Brain Res., 179: 411-424.

Jasper, H.H. (1949) Diffuse projection systems: the integrative action of the thalamic reticular system. Electroenceph. clin. Neurophysiol., 1: 405-420.

Jasper, H.H. (1954) Functional properties of the thalamic reticular system. In F. Delafresnaye (Ed.), Brain Mechanisms and Consciousness, Blackwell, Oxford, pp. 374-401.

Jasper, H.H. (1958) Report of the Committee of Clinical Examination in Electroencephalography. Electroenceph. clin. Neurophysiol., 10: 370-375.

Koch, E. (1932) Die Irradiation der pressoreceptorischen Kreislaufreflexe. Klin. Wschr, 11:225-227.

Komisaruk. B. (1977) The role of rhythmical brain activity in sensorimotor integration. In J. Sprague and A. Epstein (Eds.), Progress in Psychobiology and Physiological Psychology, Vol. 7, Academic Press, New York, pp. 55-90.

Lacey, B.C. and Lacey, J.I. (1974) Studies of heart rate and other bodily processes in sensorimotor behavior. In P.A. Obrist, A.H. Black, J. Brener and L.V. DiCara (Eds.), Cardiovascular Psychophysiology, Aldine, Chicago, pp. $538-564$

Lacey, J.I. (1967) Somatic response patterning and stress: some revisions of activation theory. In M.H. Appley and R. Trumbull (Eds.), Psychological Stress: Issues in Research. Appleton-Century-Crofts, New York, pp. 14-44.

Lacey, J.I. (1972) Some cardiovascular correlates of sensorimo- tor behavior: examples of visceral afferent feedback. In C.B. Hockman (Ed.), Limbic System Mechanisms and Autonomic Function, Thomas, Springfield, IL, pp. 175-196.

Lacey, J.I., Kagan, J., Lacey, B.C. and Moss, H.A. (1963) The visceral level: situational determinants and behavioral correlates of autonomic response patterns. In P.G. Knapp (Ed.), Expression of the Emotions in Man, International Univ. Press, New York, pp. 161-196.

Lansing, R.W. (1957) Relation of brain and tremor rhythms to visual reaction time. Electroenceph. clin. Neurophysiol., 9: 497-504.

Lindsley, D.C. (1952) Psychological phenomenon and the electroencephalogram. Electroenceph clin. Neurophysiol., 4: 433-456.

Morison, R.S. and Dempsey, E.W. (1942) A study of thalamocortical relations. Amer. J. Physiol., 135: 281-292.

Nakao, H., Ballim, H. and Gellhorn, E. (1956) The role of the sinoaortic receptors in the action of adrenaline, noradrenaline and acetylcholine on the cerebral cortex. Electroenceph. clin. Neurophysiol., 8: 413-420.

Nunn, C.M.H. and Osselton, J.W. (1974) The influence of the EEG alpha rhythm on the perception of visual stimuli. Psychophysiology, 11: 294-303.

Obrist, P.A. (1976) The cardiovascular behavior interaction-- as it appears today. Psychophysiology, 13: 95-107.

Ohmoto, T., Mimura, Y., Baba, Y., Miyamoto, T., Matsumoto, Y., Nishimoto, A., and Matsumoto, K. (1978). Thalamic control of spontaneous alpha rhythm and evoked responses. Appl. Neurophysiol., 41: 188-192.

Ponte, J. and Purves, M.J. (1974) The role of carotid body chemoreceptors and carotid sinus baroreceptors in the control of cerebral blood vessels. J. Physiol., 237: 315-340.

Remond, A and Lesevre, N. (1967) Variations in average visual evoked potential as a function of the alpha rhythm phase ("Autostimulation"). Electroenceph. clin. Neurophysiol. Suppl. 26: 42-52.

Sandman, C.A., McCanne, T.R., Kaiser, D.N. and Diamond, B. (1977) Heart rate and cardiac phase influences on visual perception. J. comp. physiol. Psychol., 91: 189-202.

Voogd, R.N.J. and Huijzen, C. (1979) The Human Central Nervous System, Springer Verlag, New York.

Walker, B.B. and Sandman, C.A. (1979) Human visual evoked responses are related to heart rate. J. comp. physiol. Psychol. 93: 717-729.

Walker, B.B. and Sandman, C.A. (1982) Visual evoked potentials change as heart rate and carotid pressure change. Psychophysiology, 19: 520-527. 